\title{
Variability, association and genetic divergence analysis in Chench (Corchorus acutangulus Lam.): A Popular Leafy Vegetable of Chhattisgarh, India- A Review
}

\author{
Vivek Kumar Kurrey*, Pravin Sharma, Amit Dixit, \\ Ishwar Singh Diwan and Arti Kujur \\ Department of Vegetable Science, Indira Gandhi Krishi Vishwavidyalaya, \\ Raipur - 492 012, Chhattisgarh, India \\ *Corresponding author
}

\section{A B S T R A C T}

Keywords

Chench, Corchorus acutangulus Lam., genetic variability. Divergence, Correlation and Path analysis

Article Info

Accepted:

30 December 2017

Available Online:

10 January 2018
In India, the leaves of a large number of wild and cultivated plants are used as leafy vegetables. They have a very high protective food value and are very easy to grow. The use of leafy vegetables as food has been formed an integral part of the culture and tradition of many indigenous communities of the world. It constitutes an essential component in the diet and food security of many tribal and local communities particularly people living around the forest fringe. In Chhattisgarh, the life and economy of the tribal and local people are intimately connected with the natural vegetation. Leafy vegetables play a major role in the nutritional requirement of the tribal and local population in remote parts of the Chhattisgarh. Leafy vegetables are not only important as food but it also fulfill the regular requirement of nutrients

\section{Introduction}

Chench (Corchorus acutangulus Lam.) is one of the unexploited and underutilized leafy vegetable and also know as vegetable jute in India. In Chhattisgarh, it is popularly known as Chench Bhaji and belongs to the family Tiliaceae. Chench is an annual herb, green leaves along with tender petiole and soft stem from a wide range of plants are consumed as a leafy vegetable.
The $100 \mathrm{~g}$ of fresh edible portion of chench bhaji contain is water (81.4 g), energy (58 $\mathrm{kcal})$, protein $(5.1 \mathrm{~g})$, fat $(1.1 \mathrm{~g})$, carbohydrate $(8.1 \mathrm{~g})$, fibre $(1.6 \mathrm{~g}), \mathrm{Ca}(241 \mathrm{mg}), \mathrm{P}(83 \mathrm{mg})$, $\mathrm{Fe}(7.2 \mathrm{mg})$ and ascorbic acid $(80 \mathrm{mg})$ (Gopalan et al., 2004). The bitterness in Corchorus Leaves is due to Corchorin Glycosides. Green leafy vegetables are good source of folic acid and antioxidant 
properties. The roots and leaves are said to cure gonorrhea and urethral discharge the seeds are stomachic and used in pneumonia. The plant is said to possess anticancer antipyretic, anticonvulsant, stomachic and digitalis glycoside like action whereas, leaves and arial parts of Corchorus acutangulus Lam. possess antibacterial potential (Patel, 2011). Moreover, Corchorus is known to contain high levels of iron and folate which are useful for the prevention of anaemia (Steyn et al., 2001).

The information on the genetic variability and its components and the correlation component characters with green leaf yield is required. It is a well known fact that the yield is a polygenic trait and greatly affected by environment. Thus the selections based on yield component have better chance of success. It is therefore, necessary to have knowledge of direct and indirect influences of yield attributing characters, which help to select best performing genotype.

\section{Genetic variability}

The genetic improvement in any crop plants primarily depends on the magnitude of available genetic variability. There are two kinds of variability in crop plants, genetic and non genetic. The study of genetic variability was made for the first time by the great biologist, Fisher (1918) and subsequently the estimates of genotypic and phenotypic variations were used to predict the expected genetic response.

Das and Kumar (2012) studied 32 jute (Corchorus spp.) varieties comprised of 18 olitorius and 14 capsularis and found PCV and GCV were highest for 1000 seed weight (33.78 and $33.29 \%$ respectively) followed by fibre fineness (27.11 and $26.70 \%$ respectively). Low variability was recorded in case of plant height. Denton and
Nwangburuka (2012) revealed fifteen accessions of leaf $C$. olitorius and found high variability between number of leaves per plant, plant height at maturity, fresh leaf weight, total plant weight and harvest index. Ghosh et al. (2013) studied 63 jute genotypes, including 2 varieties with 37 accessions of $C$. capsularis and 1 variety with 23 accessions of C. olitorius, were evaluated to assess the extent and patterns of variability and found that seed traits exhibited a wider range of variation than fiber traits and the genotypes in $C$. olitorius varied the most than those in $C$. capsularis. Hasan et al. (2013) evaluated seventeen genotypes of stem amaranth (Amaranthus tricolor L.). The genotypes varied significantly for all the characters studied. High GCV and PCV were observed in leaf weight (77.54 and 80.14 \%, respectively) and dry weight without rind (74.42 and $74.47 \%$, respectively). Khurana et al. (2013) observed that the analysis of variance was highly significant differences for all the parameters in 24 genotypes of Amaranthus spp. Phenotypic coefficient of variation (PCV) was higher than those of genotypic coefficient of variation (GCV) in both seasons for all the characters in all the cuttings. Gerrano et al. (2014) studied 32 genotypes Amaranthus spp. and reported the analysis of variance showed highly significant differences among the Amaranthus species for all phenotypic traits, indicating the existence of high genetic variability. Praveen et al. (2014) studied eight genotypes of Amaranthus spp. and found existence of considerable amount of genetic variability for all the traits except leaf length in 60 days. PCV is highest in the character no. of leaves/plant in 60 days and lowest in the character no. branch number/ plant in 90 days. Sarkar et al. (2014) studied genotypic variability in 30 vegetable amaranth genotypes for nutrient composition, antioxidant content and 12 yield contributing traits. High range of variability and high genotypic variance were observed for all the 
traits except content of $\mathrm{Ca}$, protein and beta carotenoid. Vujacic et al. (2014) reveled 10 amaranth genotypes and found variability in total leaf mass per plant ranging from $94.05 \mathrm{~g}$ to $246.81 \mathrm{~g}$, grain yield per plant ranging from $45.56 \mathrm{~g}$ to $67.55 \mathrm{~g}$, as well as total grain yield ranging from $2220 \mathrm{~kg} / \mathrm{ha}$ to $3200 \mathrm{~kg} / \mathrm{ha}$.

\section{Heritability and genetic advance}

The term heritability in broad sense can be defined as the ratio of genetic variance to the total phenotypic variance (Lush, 1940). It is generally expressed in percentage. Thus the heritability is the heritable portion of phenotypic variance which is good index of the transmission of characters from parents to their offspring (Falconer, 1960). Depending upon the components of variance used as numerator in the calculation, heritability is of two type's viz. broad sense heritability and narrow sense heritability.

Heritability estimate provides the information regarding the amount of transmissible genetic variation to total variation and determines genetic improvement and response to selection Shukla et al. (2005) evaluated 29 strains of vegetable amaranth (A. tricolor) and observed the heritability estimates were in general high for all the characters in the entire cuttings and ranged from $74.87 \%$ to $93.33 \%$. Genetic advance was maximum for foliage yield $(42.50 \%)$ followed by leaf size $(31.02 \%)$ and stem diameter (21.13\%). Shukla et al. (2006) studied twenty nine strains of vegetable amaranth (Amaranthus tricolor L.). The high heritability was estimates for all the traits in all the cuttings as well as on pooled basis. Highest expected genetic advance was noticed for ascorbic acid (57.48\%) followed by foliage yield $(48.30 \%)$ and leaf size (29.51\%). Anuja and Mohideen (2007 a) studied genetic variability and heritability in 100 genotypes of amaranthus germplasm and found heritability estimates in general were high for most of the characters. High heritability coupled with high genetic advance (as percent of mean) was observed for number of leaves, root length, root weight, leaf weight and stem weight. Pan et al. (2008) evaluated 24 indigenously collected germplasm of $A$. tricolor including two released varieties and found that heritability was high for leaf stem ratio, width of leaf, length of leaf, days to $1^{\text {st }}$ clipping, number of clipping, girth of stem and total yield of greens per plot. High heritability along with high genetic advance was observed for leaf-stem ratio, width of leaf, total yield of greens/plot and length of leaf. Varalakshmi and Devaraju (2010) revealed eleven germplasm lines of the Indian spinach (basella) and found that moderate heritability along with high genetic advance was recorded for leaf weight and total plant weight, indicating the presence of additive gene effects. Das and Kumar (2012) studied 32 jute (Corchorus spp.) varieties comprised of 18 olitorius and 14 capsularis and high heritability was recorded for time of $50 \%$ flowering (99\%) followed by fibre fineness and seed weight (97\%). Navangburuka and Denton (2012) evaluated 15 genotypes of Corchorus olitorius and reported high estimates of broad sense heritability was recorded in no of leaves $(96.99 \%)$, plant height at maturity (95.61\%), leaf weight per plant $(94.74 \%)$, total weight per plant (97.02 $\%$ ) and harvest index (75.00\%) suggesting additive gene effect in the expression of these characters. Ahammed et al. (2013) evaluated 22 genotypes of stem amaranth and found heritability estimates in broad sense were higher for leaf weight per plant $(91.10 \%)$ followed by leaves per plant $(86.83 \%)$, primary branches per plant $(86.42 \%)$, stem weight per plant $(82.56 \%)$ and yield per hectare $(78.70 \%)$. Leaf weight per plant, stem weight per plant and yield per hectare exhibited high value of heritability $(91.10 \%$, $82.56 \%$ and $78.70 \%$ respectively) along with high genetic advance $49.38 \%, 134.12 \%$ and 
$56.00 \%$ for leaves per plant, stem diameter and stem weight per plant, respectively. Hasan et al. (2013) evaluated seventeen genotypes of stem amaranth (Amaranthus tricolor L.) and observed high heritability coupled with high genetic advance as percent of mean was registered for number of leaf, leaf weight and marketable yield which in fact demonstrated the presence of additive gene effects. Praveen et al. (2014) studied 8 of Amaranthus spp. and found that high estimate of heritability was also observed for the characters of seed yield/plant, length of inflorescence and genetic advance shows the character seed weight of 1000 seeds, seed yield/plant, and inflorescence/plant. Sawarkar et al. (2014) studied thirty genotypes of tossa jute (Corchorus olitorius L.) and found high values of heritability (>90\%) for almost all characters like plant height $(93.01 \%)$, bark thickness $(98.33 \%)$, base diameter $(94.82 \%)$, green weight (91.64\%), stick weight $(99.20 \%)$ and fibre weight $(96.48 \%)$. The high heritability with moderate to high genetic advance over percentage of mean was observed in bark thickness (98.33 and 38.86 $\%$ ), stick weight $(99.20$ and $56.87 \%$ ) and fibre weight (96.48 and $25.02 \%$ ) which indicate preponderance of additive genetic action. Venkatesh et al. (2014 b) studied one hundred germplasm accessions of grain amaranth, all the traits studied exhibited high heritability. High genetic advance as per cent of mean was observed for days to 50 percent flowering, stem girth, number of leaves per plant, plant height, panicle length, panicle width and grain yield per plant Vujacic et al (2014) studied ten amaranth genotypes and observed that heritability varied from $86 \%$ (grain weight per plant) to $92 \%$ (leaf mass per plant).

\section{Correlation coefficient studies}

Correlation coefficient is a statistical measure which is used to find out the degree and direction of relationship between two or more variables. The original concept of correlation was represented by Galton (1888) and he suggested the need of coefficient of correlation to describe the degree of association between variables. Later the theory of correlation was developed by Pearson (1904). Thereafter, Searle (1961) described the mathematical implications of correlation coefficient at phenotypic, genotypic and environmental level.

Pan et al. (2008) studied 24 indigenously collected germplasm of (A. tricolor) and reported that the total yield of greens/plot was found to be positively and significantly correlated with duration of harvest. Shukla $e t$ al. (2010) evaluated 39 distinct cultivars of vegetable amaranth (A. tricolor). Among the agronomic traits, plant height and number of inflorescence exhibited significant positive association with foliage yield, while chlorophyll a, chlorophyll b, carotenoid, fiber and ascorbic acid were positively correlated with foliage yield. Chlorophyll a and chlorophyll b exhibited significant positive association with carotenoid, fiber and ascorbic acid. Ascorbic acid was positively correlated with fiber and carotenoid. Navangburuka and Denton (2012) evaluated 15 genotypes of Corchorus olitorius and reported strong positive genotypic and phenotypic correlation between no. of leaves per plant and plant height at maturity $(0.43,0.45)$, leaf weight per plant $(0.86,0.87)$, total plant weight $(0.81$, $0.82)$ and harvest index $(0.33,0.38)$. Ahammed et al. (2013) evaluated 22 genotypes of stem amaranth and reported leaf weight per plant and plant height exhibited highly significant positive correlation with yield per hectare both at genotypic and phenotypic level. Akaneme and Ani (2013) studied 5 accessions of Amaranthus hybridus and reported that days to $50 \%$ flowering were positively correlated with leaf length and stem diameter. Arif et al. (2013) studied 35 
different accessions of spinach for various traits. The evaluation was based on 20 qualitative and quantitative parameters and found number of leaves per plant showed positive and significant correlation with leaf length and leaf width. It was significant only with earliness of bolting and days to flowering. The existing of was reported positive and significant correlation between days to flowering and days to harvesting was reported. Earliness of bolting also remained significantly correlated with days to flowering. A negative association among several traits was also observed which was non-significant. Ghosh et al. (2013) evaluated 63 jute (C. capsularis) genotypes and found significant positive correlations of fiber yield with days to $50 \%$ flowering (0.60), plant height at average flowering (0.72), plant base diameter (0.74) and fresh weight (0.90), whereas, leaf angle was negatively (-0.52) correlated. Seed yield was significantly positively correlated with pod length $(0.72)$ and seeds per pod (0.79). Khurana et al. (2013) studied 24 genotypes of Amaranthus spp. and reported that total green yield was negatively correlated with oxalate content and leaf blight incidence. Plant height was positively correlated with number of branches per plant $(0.6491)$, leaf length $(0.3381)$, leaf width (0.41954), number of leaves per plant (0.5254), leaf area index (0.5604), total green yield (0.5632) and protein content (0.4271). Number of leaves per plant was positively correlated with leaf area index (0.9210), total green yield (0.9529) and protein content (0.7836).Number of leaves was negatively correlated with oxalate content $(-0.3429)$ and leaf blight incidence (-0.8577). Kendre et al. (2013) studied twenty genotypes of amaranth and revealed that, plant height and petiole length exhibited positive and significant association with the yield in amaranth which indicated their relative importance in leaf yield. However, there were exhibited significant correlation coefficient value, which indicated that the indirect effects of plant height Hasan et al. (2013) evaluated 17 genotypes of stem amaranth (Amaranthus tricolor L.) were revealed that green yield was positive correlated with leaf weight, stem weight, stem diameter, dry weight with rind, and dry weight without rind. Sarkar et al. (2014) studied thirty vegetable amaranth genotypes and reported that foliage yield had significant positive correlation with plant height, leaves per plant, diameter of stem base, fiber content and leaf area. Nutrient content and antioxidant had insignificant genotypic correlations with foliage yield. Hailu et al. (2015) evaluated 36 accessions of Amaranthus spp. and found that the green leaf yield per plant showed positive and significant relationship with stem diameters, plant height, inter nod length, top branch and average branch length and highly significant relation with days to emergence, days to green harvest, days to flowering, number of leaf per plant, biomass per plant, days to seed harvest, leaf width, leaf area, primary and secondary branch per plant.

\section{Path coefficient analysis}

Path coefficient analysis is carried out using the estimates of correlation coefficient. The concept of path coefficient analysis was originally developed by Wright in 1921, but the technique was first used for plant selection by Dewey and Lu (1959). Path coefficient analysis is simply a standardized partial regression coefficient which splits the correlation coefficient into the measures of direct and indirect effects. In other hands, it measures the direct and indirect contribution of various independent characters on a dependent character.

Pan et al. (2008) 24 indigenously collected germplasm of (A. tricolor) including two released varieties. Path coefficient analysis of different characters contributing towards total 
yield of greens revealed that duration of harvest had maximum positive direct effect on total yield. The indirect effect of duration of harvest via. number of clippings was maximum and positive. Shukla et al. (2010) evaluated 39 distinct cultivars of vegetable amaranth (A. tricolor). Protein was associated with plant height, branches per plant and 500 seed weight. Chlorophyll a, carotenoid and inflorescence length revealed high positive direct effect on foliage yield, while branches plant per plant, leaf size, seed yield, chlorophyll b, moisture content and ascorbic acid showed negative path coefficient with foliage yield. Varalakshmi and Devaraju (2010) evaluated eleven germplasm lines of the Indian spinach (Basella) and reported that higher plant weight was found to be significantly and positively associated with branch number, leaf number, leaf weight and stem weight. Leaf number had the maximum direct positive effect on total plant weight, followed by leaf length. Indirect effects of other characters through these characters were also seen to be positive. Selvaraj and Kanthaswamy (2012) studied 74 genotypes of amaramthus and path analysis revealed that the highest direct effect of number of leaves, leaf length, and leaf breadth, stem girth and plant weight towards weight of leaves. The indirect effect of most of the characters through number of leaves, leaf length and leaf breadth. Hasan et al. (2013) evaluated seventeen genotypes of stem amaranth (Amaranthus tricolor L.) were evaluated that path analysis indicated that stem weight had maximum direct effect on marketable yield followed by leaf weight, leaf number and dry weight without rind. Kendre et al. (2013) studied twenty genotypes of amaranth path analysis revealed that, the character viz. stem diameter exerted highest direct effect over yield followed by petiole length, leaf area and number of leaves. While, plant height character exhibited the negative direct effect on yield, however exhibited significant correlation coefficient value, indicated that the indirect effects of plant. Sarker et al. (2014) studied thirty vegetable amaranth genotypes and reported that the fiber content (0.616), leaf area (0.464), diameter of stem base (0.420) and betacarotenoid (0.347) had high positive direct effect on foliage yield. Hailu et al. (2015) studied 36 accessions of Amaranthus spp. and found that the highest and positive direct effect was exerted by biomass per plant followed by average branch length and characters had significant correlations with green leaf yield.

\section{Genetic divergence}

The concept of $\mathrm{D}^{2}$ statistics was originally developed by Mahalonobis (1936). Then, Rao (1952) suggested the application of this technique for the arrangement of genetic diversity in plant breeding. Now, this technique is extensively used in vegetable breeding for the study of genetic divergence in the various breeding material including germplasm. This analysis also helps in the selection of diverse parents for the development of hybrids. Cluster analysis helps to form groups of closely related individuals which help in determining genetic distance between them.

Ahammed et al. (2013) evaluated 22 genotypes of stem amaranth and grouped into four clusters. Cluster I, II, III and IV composed of two, four, seven and nine genotypes in succession. Maximum inter cluster distance (12.326) was observed between cluster I and III and it was minimum (3.526) between cluster I and II. The crosses between the genotypes of cluster I with that of cluster III and cluster II with cluster III would exhibit high heterosis and also likely to produce new recombinants with desired characters in stem amaranth. The yield contributing characters were leaves per plant, petiole length, stem diameter, leaf weight per 
plant and stem weight per plant. Leaf width, petiole length and 1000 seed weight showed maximum contribution to the total divergence. Akaneme and Ani (2013) studied five accessions of the Amaranthus hybridus. The dendrogram divided the accessions into cluster 1 comprising accessions 3 and 5 and cluster 2 comprising accessions 1, 2, 4. The qualitative traits differed among the accessions with the exception of growth habit, branching index and leaf shape. Akther et al. (2013) revealed seventeen genotypes of stem amaranth (Amaranthus tricolor L.). The genotypes under study fell into 4 clusters. The distribution pattern indicated that the maximum number of genotypes (6) was included in cluster (IV) followed by cluster III (5) and cluster II (5), and the minimum number was in cluster I (1). The inter cluster distance in most of the cases was higher than the intra cluster distance, which indicated wider genetic diversity among the accessions of different groups. The highest inter cluster distance was observed between IV and I, followed by the distance between cluster II and I showing wide diversity among the groups. The lowest inter-cluster distance was observed between clusters III and II suggesting a close relationship among the genotypes of these two clusters. The highest intra-cluster distance was observed for the cluster IV and the lowest for the cluster I. Arif et al. (2013) studied 35 different accessions of spinach the accessions under study fell into 4 cluster, cluster-I was the largest, comprising of 17 genotypes, cluster-II of 7 accessions, cluster-III 4 genotypes while cluster-IV contained 7 genotypes. The germplasm grouped in cluster-I were of medium plant height, late flowering, more tillers and late in bolting. The germplasm contained in clusterII were characterized with more leaf per plant, longer leaves and the highest plant height. Spinach accessions grouped in cluster-III had high number of leaves per plant, larger leaf length and more plant height, while the germplasm in cluster-IV reflected the highest number of leaves per plant as well as leaf length and width, moderate plant height, moderate maturity and moderate petiole length. Ghosh et al. (2013) evaluated 63 jute (C. capsularis) genotypes and found the clustering patterns and suggested that the two jute species are distantly related. The highest diversity (0.69) was observed between clusters IX and IV, whereas clusters III and IV showed the greatest similarity (0.14).

\section{References}

Ahammed, A. U., Rahman, M. M. and Mian, M. A. K. 2013. Mutivariate analysis in stem amaranth (Amaranthus tricolor). Bangladesh Journal of Plant Breeding and Genetics, 26(1): 11-17.

Akaneme, F. I. and Ani G. O. 2013. Morphological Assessment of Genetic Variability among Accessions of Amaranthus hybridus. World Applied Sciences Journal. 28 (4): 568-577.

Akther, C.A., Hasan, M., Raihan,M.S., Hossain M.M. and Mian, M.A.K. 2013. Genetic Divergence in Stem Amaranth (Amaranthus tricolor L.) Genotypes for Yield and its Component Characters. The Agriculturists. 11(1): 82-88.

Anuja, S, and Mohideen, M.K. 2007 a. Variability, heritability and genetic advance studies in amaranthus (Amaranthus spp.). The Asian Journal of Horticulture, 2 (1): 63.

Arif, M., Jatoi, S.A., Rafique, T. and Ghafoor, A. 2013. Genetic divergence in indigenous spinach genetic resources for agronomic performance and implication of multivariate analyses for future selection criteria. Sci., Tech. and Dev., 32 (1): 7-15.

Das, A. and Kumar, D. 2012. Genetic evaluation and characterization of jute (corchorus spp. L) genotypes using DUS parameters. SAARC J. Agri., 10(2): 147- 
153.

Denton, O.A. and Nwangburuka, C.C. 2012. Morphological diversity among Corchorus olitorius accessions based on Single linkage cluster analysis and principal component analysis. Jordan Journal of Biological Sciences. 5(3):191-196.

Dewey, D. R. and Lu, K. H. 1959. A correlation and path coefficient analysis of components of crested wheat grass seed production. Agron. J., 51: 512-515.

Falconer, D. S. 1960. Introduction to Quantitative Genetics. Oilver and Boyd, Edinburgh and London. Pp. 365.

Fisher, R. A. 1918. The correlation among relatives on the supposition of mendelian Inheriatnce. Aust. J. Agric. Res., 14: 742-757.

Galton, P. 1888. Correlation and their measurement a chiefly from athropometric data. Proc. Royal Soc., 45: 135-145.Jackson, M.L.1973. Soil Chemical analysis. Prentice-Hall of India Pvt Ltd., New Delhi.

Gerrano, A. S., Rensburg, W. S. J. and Adebola, $\quad$ P. $\quad$ O. 2014. Agro-morphological variability of Amaranthus genotypes in South Africa. Acta Horticulturae, 11(1035): 183-187.

Ghosh, R.K., Sreewongchail, T., Nakasathien, S. and Phumichai, C. 2013. Phenotypic variation and the relationships among jute (Corchorus species) genotypes using morphoagronomic traits and multivariate analysis, Australian Journal of Crop Science, 7(6): 830-842.

Gopalan. C, Rama Sastri B.V. and Balasubramanian, S.C. 2004. Nutritive Value of Indian Foods, National Institute of Nutrition, ICMR, Hyderabad.

Hailu, H. F., Lal, S. and Alameraw, S. (2015). Estimation of Association Characters in Amaranths Germplasm Accessions
(Amaranthus spp.)

Hasan, M., Akther, C.A. and Raihan, M.S. 2013. Genetic Variability, Correlation and Path Analysis in Stem Amaranth (Amaranthus tricolor L.) Genotypes. The Agriculturists, 11(1): 1-7.

Kendre, V., Dod, V. N., Nagre, P. K., Kale, V. S. Potdukhe, N. R. 2013. Correlation and path analysis in leafy Amaranthus tricolor L., Annals of Plant Physiology, 27(1/2): 27-29.

Khurana, D.S., Singh J. and Kaur, B. 2013. Genetic variability, correlation and path coefficient anlaysis in amaranthus. Vegetable Science, 40(2): 238-240.

Lush, J. L. 1940. Intra-sire correlation and regression of offspring on dam as a method of estimation heritability of characteristics. Proc. Amercian Science An. Prod., 301 - 392.

Mahalanobis, P. C. 1936. On the generalized distance in statistics. Proc. Nat. Inst. Sci., India, 21: 49-55.

Nwangburuka, C.C. and Denton, O.A. 2012. Heritability character association and genetic advance in six agronomic and yield related characters in leaf Corchorus olitorius, International journal of agricultural research, 7(7): 367-375.

Pan, R.S., Singh, A.K., Kumar, S. and Rai, M. 2008. Genetic variation and character association in vegetable amaranth (Amaranthus tricolor L.). Veg. Sci. 35(1): 81-83.

Parveen, M., Chattopadhyay, N.C. and Tah, J. 2014. Strategy of biometric evaluation of vegetative yield attributes of Amaranth cultivars. Bioscience Discovery, 5(1): 70-73.

Parveen, M., Chattopadhyay, N.C. and Tah, J. 2014. Strategy of biometric evaluation of vegetative yield attributes of Amaranth cultivars. Bioscience Discovery, 5(1): 70-73.

Patel, R. 2011. Evaluation of antibacterial activity of methanol extracts of leaves 
and arial parts of Corchorus aestuans Linn., International research journal of pharmacy, 2(5): 228- 230.

Pearson, A. K. 1904. On the generalized theory of alternative inheritance with special reference to Mendel's law. Phil. Trans. Roy. A., 203: 53 - 86.

Rao, C. R. 1952. Advance Statistical Methods in Biometrics Research. Hofaer Pub. Darion. pp. 371-378.

Sarker, U., Islam, T., Rabbani, G. and Oba, S. 2014. Genotypic variability for nutrient, antioxidant, yield and yield contributing traits in vegetable amaranth. Journal of Food, Agriculture \& Environment, 12 (3\&4): 168-174.

Sawarkar, A.,Yumnam, S., Patil, S.G. and Mukherjee, S. 2014. Correlation and path coefficient analysis of yield and its attributing traits in tossa jute (Corchorus olitorius L.). The bioscan, 9(2): 883-887.

Searle, S. R. 1961. Phenotypic, genotypic and environmental correlation, Biometrics, 17: 474-480.

Shukla, S., Bhargava, A., Chatterjee, A., Srivastava, A. and Singh, S. P. 2006. Estimates of genetic variability in vegetable amaranth (A. tricolor) over different cuttings. Hort. Sci., 32(2): 6067.

Shukla, S., Bhargava, A., Chatterjee, A., Pandey, A.C. and Kumar, A.R.A., 2010. Genetic interrelationship among nutritional and quantitative traits in the vegetable amaranth, Crop Breeding and Applied Biotechnology 10: 16-22.

Shukla, S., Bhargava, A.,Chatterjee, A., Srivastava, A. and Singh S.P. 2005 b. Estimates of genetic variability in vegetable amaranth (A. tricolor) over different cuttings, Hort. Sci. (Prague), 32(2): 60-67.

Steyn NP, Olivier J, Winter P, Burger S, Nesamvuni S (2001) A survey of wild, green, leafy vegetables and their potential in combating micronutrient deficiencies in rural populations. S Afr J Sci 97: 276-279.

Varalakshmi, B. and Devaraju, 2010. Genetic variability in Indian spinach (Basella alba L.), J. Hortl. Sci., 5(1): 21-24.

Venkatesh, L., Murthy. N. and Nehru S. D. Manjappa, 2014 b. Genetic variability, heritability and genetic advance in grain amaranth (Amaranthus spp.), Asian Journal of Bio Science, 9(1): 67-70.

Vujacic,V., Momirovic, G.S., Perovic, D. and Nikolic, A. 2014. Variability, heritability and classification of Amaranthus spp. L. genotypes by chierarchical analysis, Romanian Agricultural Research, 21: 6067.

Wright, S. 1921. Correlation and causation. J. Agric. Res., 20: 557-585.

\section{How to cite this article:}

Vivek Kumar Kurrey, Pravin Sharma, Amit Dixit, Ishwar Singh Diwan and Arti Kujur. 2018. Variability, association and genetic divergence analysis in Chench (Corchorus acutangulus Lam.): A Popular Leafy Vegetable of Chhattisgarh, India- A Review. Int.J.Curr.Microbiol.App.Sci. 7(01): 3603-3611. doi: https://doi.org/10.20546/ijcmas.2018.701.423 